\title{
Building Information Modeling (BIM) for Construction and Demolition Waste Management in Australia: A Research Agenda
}

\author{
Dongchen Han*D, Mohsen Kalantari and Abbas Rajabifard \\ Department of Infrastructure Engineering, Faculty of Engineering and IT, The University of Melbourne, \\ Melbourne, VIC 3000, Australia; mohsen.kalantari@unimelb.edu.au (M.K.); abbas.r@unimelb.edu.au (A.R.) \\ * Correspondence: dongchenh@student.unimelb.edu.au; Tel.: +61-434279825
}

Citation: Han, D.; Kalantari, M.; Rajabifard, A. Building Information Modeling (BIM) for Construction and Demolition Waste Management in Australia: A Research Agenda. Sustainability 2021, 13, 12983. https:/ / doi.org/10.3390/su132312983

Academic Editor: Antonis A. Zorpas

Received: 8 September 2021

Accepted: 17 November 2021

Published: 24 November 2021

Publisher's Note: MDPI stays neutral with regard to jurisdictional claims in published maps and institutional affiliations.

Copyright: (c) 2021 by the authors. Licensee MDPI, Basel, Switzerland. This article is an open access article distributed under the terms and conditions of the Creative Commons Attribution (CC BY) license (https:// creativecommons.org/licenses/by/ $4.0 /)$.

\begin{abstract}
Construction and demolition waste (C\&DW) contribute to approximately $30 \%$ of the total waste generation worldwide, by which heterogeneous ecological impacts, such as resource depletion, global warming, and land degradation, are engendered. Despite ongoing research efforts to minimize construction waste via the Building Information Modeling (BIM)-aided design, there is a paucity of research on integrating BIM in demolition waste management (DWM). This study investigates prominent barriers and future research directions toward the wider adoption of BIM in C\&DWM by conducting a systematic literature review. First, this study identifies the barriers that hinder the implementation of C\&DWM in Australia; then, it explores the benefits and challenges of leveraging BIM applications for C\&DWM. The findings suggest that, for existing buildings without up-to-date design drawings, it is imperative to improve the accuracy of data capturing and object recognition techniques to overcome the bottlenecks of BIM-DWM integration. Moreover, the development of regional-oriented material banks and their harmonization with life cycle assessment databases can extend the potential of BIM-based sustainability analysis, making it applicable to the DWM domain. This study proposes a research agenda on tackling these challenges to realize BIM's full potential in facilitating DWM.
\end{abstract}

Keywords: C\&D waste management (C\&DWM); demolition waste management (DWM); Building Information Modeling (BIM); existing buildings; 3D reconstruction; point cloud; sustainability; life cycle assessment (LCA)

\section{Introduction}

The rapid growth of the economy and human population has accelerated urban land resources exploitation by stimulating the large-scale construction and demolition of residential buildings and infrastructure. Those activities, including land excavation, site clearance, roadwork, and building renovation, tend to produce an enormous amount of construction and demolition waste (C\&DW) [1], resulting in heterogeneous environmental problems, such as global warming, natural resource depletion, and land degradation. Moreover, $32 \%$ of global resource exploitation and $40 \%$ of virgin materials consumption can be attributed to the construction industry [2]. Under these circumstances, reinventing the entire production and distribution chain and recovering materials under a "cradle to cradle" principle ensures that the construction material flow transfer occurs in a closedloop [3]. To this end, improving resource efficiency through systematic C\&DWM provides a new perspective that is in line with the sustainable development goals (SDG) and circular economy (CE) principle.

This situation also applies to the Australian construction industry. According to the Australian national waste report [4], the total amount of waste produced domestically from 2018 to 2019 was approximately 74.1 million tons (Mt), in which C\&DW stands out as the primary contributor among diverse waste streams, accounting for $43.9 \%$ (27 Mt) of the total core waste generation (61.5 Mt). Of the $27 \mathrm{Mt}$ of C\&DW produced in 2018-2019, 
$23.2 \%$ (6.3 Mt) was sent to landfill sites, $76 \%$ (20.5 Mt) was recycled domestically, and the rest was incinerated for energy recovery. Over the past 13 years for which data are available, the C\&DW stream grew by $61 \%$ in total amount and $32 \%$ per capita, respectively [4], with most growth occurring in the last five-year span due to the unprecedented pace of urban development.

From a life cycle perspective, the benefits of C\&DW recycling typically triumph over the adverse impacts incurred by waste treatment procedures, which are embodied in reducing the carbon emission and natural resource exploitation related to raw material production [5]. In this context, industrialized countries (e.g., Australia and Japan) have progressively devoted themselves to maximizing the recycling rate of C\&DW materials, comprising masonry, metal, timber, glass, plastic, and hazardous materials [6]. Pickin et al. [4] indicated that masonry waste (e.g., bricks, concrete) generated from construction and demolition activities contributes to $73.8 \%$ of the C\&D waste and $87.7 \%$ of the entire masonry waste generation in Australia, respectively. In comparison, metal materials only constitute $2 \%$ of the total C\&DW; however, they correspond to the highest recycling rate at $90 \%$, owing to the continuously growing market price and demand for metal materials [7].

Nonetheless, sustainable development within the construction industry comprises inefficient decision-making for reuse and recycling due to inaccurate C\&DW quantification with limited data on the building materials and components [8]. Instead, general practices employ rough calculation methods, such as the "Waste index" [9] and material flow analysis method [10], to quantify C\&DW materials at the site level, where accuracy relies on data collected from site visits and industry surveys.

In recent years, the emergence of BIM technology has provided the Architecture, Engineering, and Construction (AEC) industry with an Integrated Project Delivery (IPD) approach for information management. Building information can be conveyed and exchanged seamlessly on an integrated platform throughout the project life cycle. This feature allows BIM-based applications such as design coordination, material quantity take-off (MQT), 4D phase planning, and cost estimation to be applied in the C\&DW domain [11]. More specifically, BIM can facilitate decision-making for C\&DWM planning by systematically predicting waste output, waste generation sequences, and disposal costs.

This study identifies the gap that hinders the adoption of BIM in the DWM sector. The aim is to discover solutions to these research questions listed below.

- What are the limitations of current C\&DWM practices?

- What are the benefits and barriers to the adoption of BIM for C\&DWM?

- What are the potential solutions to those challenges?

In answering these questions, this study presents a research agenda that paves the way for more effective BIM implementation in the DWM sector.

The remainder of the paper is structured as follows. Section 2 demonstrates the research methods and criteria for the collection and selection of the most relevant and peer-reviewed literature. Section 3 elucidates the limitations that hinder the effective implementation of C\&DWM and outlines the advantages of adopting BIM for availing C\&DWM. Afterward, Section 4 discusses prominent challenges of implementing BIM in DWM practices and proposes future research needs for leveraging BIM-based applications in the DWM for existing buildings. Finally, Section 5 summarizes the motivation, research outcomes, and contributions of this study.

\section{Materials and Methods}

This research adopts a systematic literature review methodology to achieve the main objective of identifying the existing challenges and future solutions to realizing BIM-based DWM. To understand the purpose and potential of utilizing BIM for tackling C\&DWM problems, the study starts by searching for answers to these research questions:

- What are the limitations of current C\&DWM practices?

- What are the benefits and barriers to the adoption of BIM for C\&DWM? 
The authors narrowed the scope of the literature search by picking a list of keyword combinations from the most cited research papers on BIM implementation in C\&DWM that were published in prestigious academic journals related to C\&DWM, BIM, and sustainability domains. The general scope of the literature is limited to journal and conference papers published from 1998 to 2021 in English. In this research, Web of Science was adopted as the main search engine based on the capabilities and comprehensiveness of its databases, whereby the most esteemed scholarly journals are indexed. The following keyword combinations were applied:

- $\quad$ BIM + C\&DW management (60)

- $\quad$ BIM + waste quantification (29)

- $\quad$ BIM + DWM + existing buildings (16)

- $\quad \mathrm{BIM}+$ point cloud + waste management (5)

- $\quad$ Automated 3D reconstruction + BIM (67)

- $\quad$ BIM + LCA + sustainability (130)

- $\quad$ BIM + LCA + waste management (30)

- $\quad \mathrm{BIM}+$ deconstruction + DWM (17)

The Web of Science database returned 354 peer-reviewed publications. Thereafter, we exported the search results to Microsoft Excel. By applying filters to delete the duplicate articles, 98 duplicates were excluded from the preliminary search. Subsequently, we refined the selection of peer-reviewed academic journals based on two appraisal criteria: the impact factor (IF) and citation score, representing the influential level and citation frequency of the studies published in the journals, respectively. Examination of the titles and abstracts from the remaining 256 papers showed that only 81 peer-reviewed academic papers closely aligned with this research topic, representing both the groundwork and state-of-the-art knowledge on BIM and C\&DWM domains.

Finally, we conducted a quick manual supplementary search, and as a result, 17 additional papers outside the initial keyword combination search were added to the final literature selection. Thus, a total number of 98 publications were reviewed in full-text and subjected to statistical analysis. Figure 1 depicts the literature selection procedures in a flow diagram.

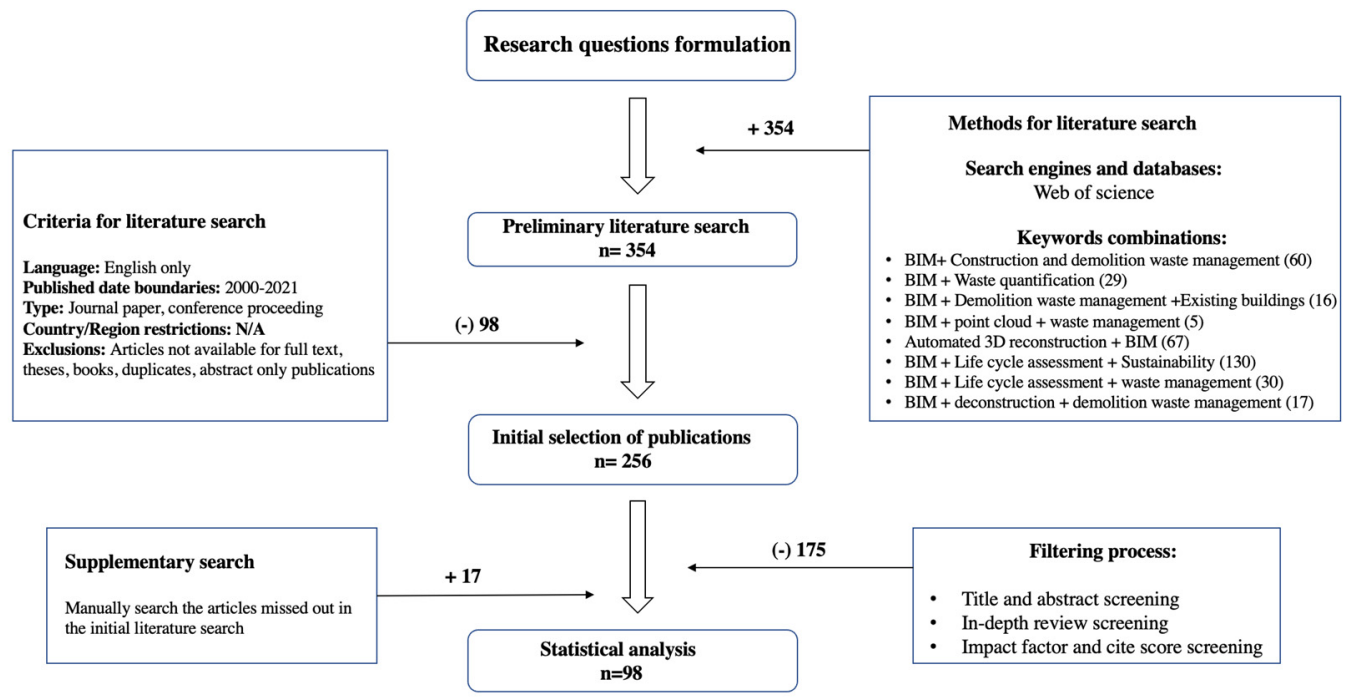

Figure 1. Systematic review procedure flow diagram.

We multiplied the number of papers published by the academic journal and the corresponding journal's impact factor that was identified from the Web of Science database; then, we divided this by the total number of papers in those journals. The weighted average "Impact Factor" of the journals selected in this research was 7.33. Similarly, the weighted average "Cite Score" was calculated as 12.58 . These results assure the credibility of the reviewed publications. Figure 2 displays the chronological distribution of reviewed paper 
numbers in each year. As shown, nearly $90 \%$ of the selected articles were published within the last 10 years, and $65 \%$ of them were published from 2015 to 2020 . Thus, it is adequate for researchers to understand the recency research trend in the C\&DWM and BIM domains. Overall, $57 \%$ of the papers were published in these four journals: Resources, Conservation, and Recycling (14), Waste Management (12), Automation in Construction (11), and Journal of Cleaner Production (10), which coincide with the groups of journals with the highest Impact Factor and Cite Score. Therefore, it validates the reliability of the theories and data derived from those papers.

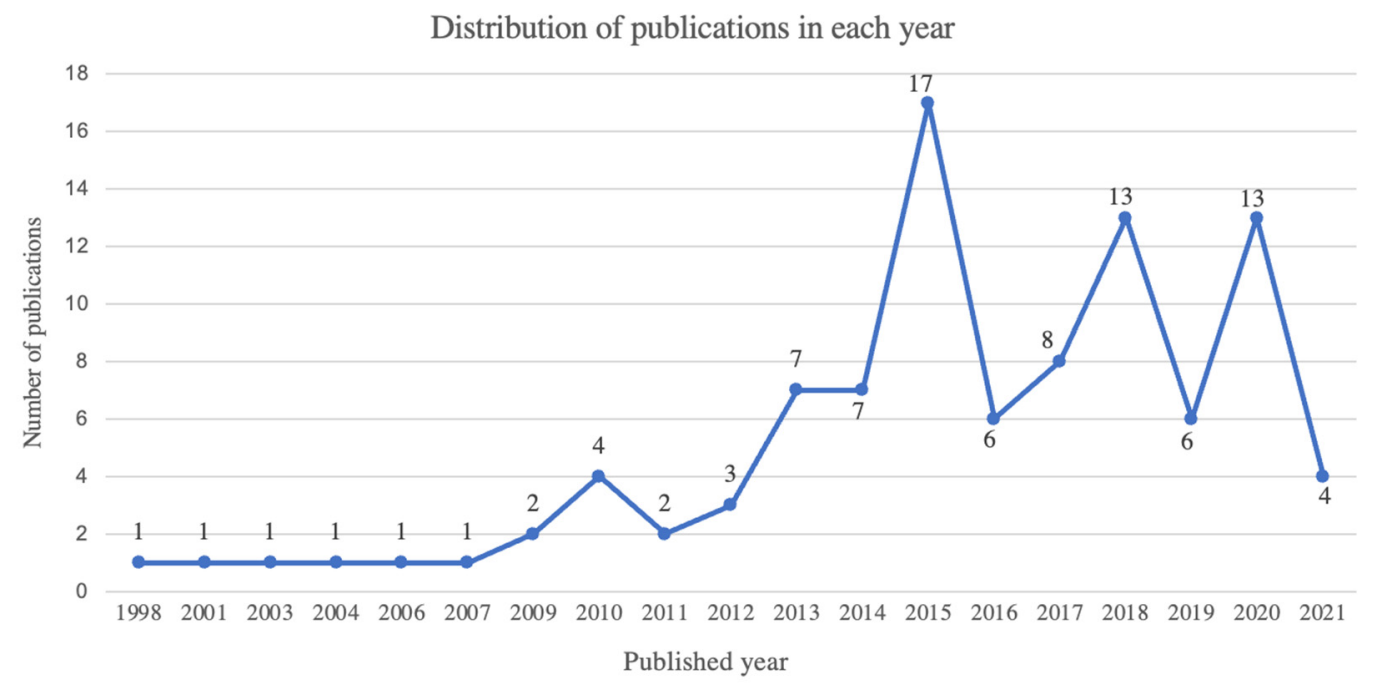

Figure 2. Chronological distribution of the number of reviewed publications in each year.

\section{Results}

\subsection{CED Waste Management Principles}

Construction and demolition activities associated with rapid urban development and population growth tend to produce a massive amount of C\&DW, which has led to multifarious environmental, economic, and societal problems. Therefore, this topic has aroused the governments' and the AEC industry practitioners' awareness of improving environmental sustainability through effective waste management practices [12-14].

Several researchers argue that taking preventive actions to minimize construction waste at its source is a more effective and sustainable strategy than adopting remedial measures [15,16]. Those waste-preventive measures can be categorized as follows: (1) minimizing construction reworks by eliminating design errors and modifications [15], (2) adopting modular construction and prefabrication $[17,18]$, and (3) avoiding residual waste via efficient construction materials procurement [19]. Figure 3 summarizes the primary sources and factors that lead to construction waste generation, which can be prevented at the design and planning stage.

The reuse of C\&DW materials refers to repeatedly employing materials in the same kind of construction procedure (e.g., formwork for concreting) or functioning as a new element in other processes like cut-corners of reinforcement bars [20]. Land reclamation, road surfacing, and substituting concrete aggregates are the typical applications for reusing demolition waste materials [21]. Compared to recycling, reuse of materials requires minimum operations of recovery. Hence, the energy consumption and environmental impacts associated with the reutilization of C\&DW are negligible [22]. 


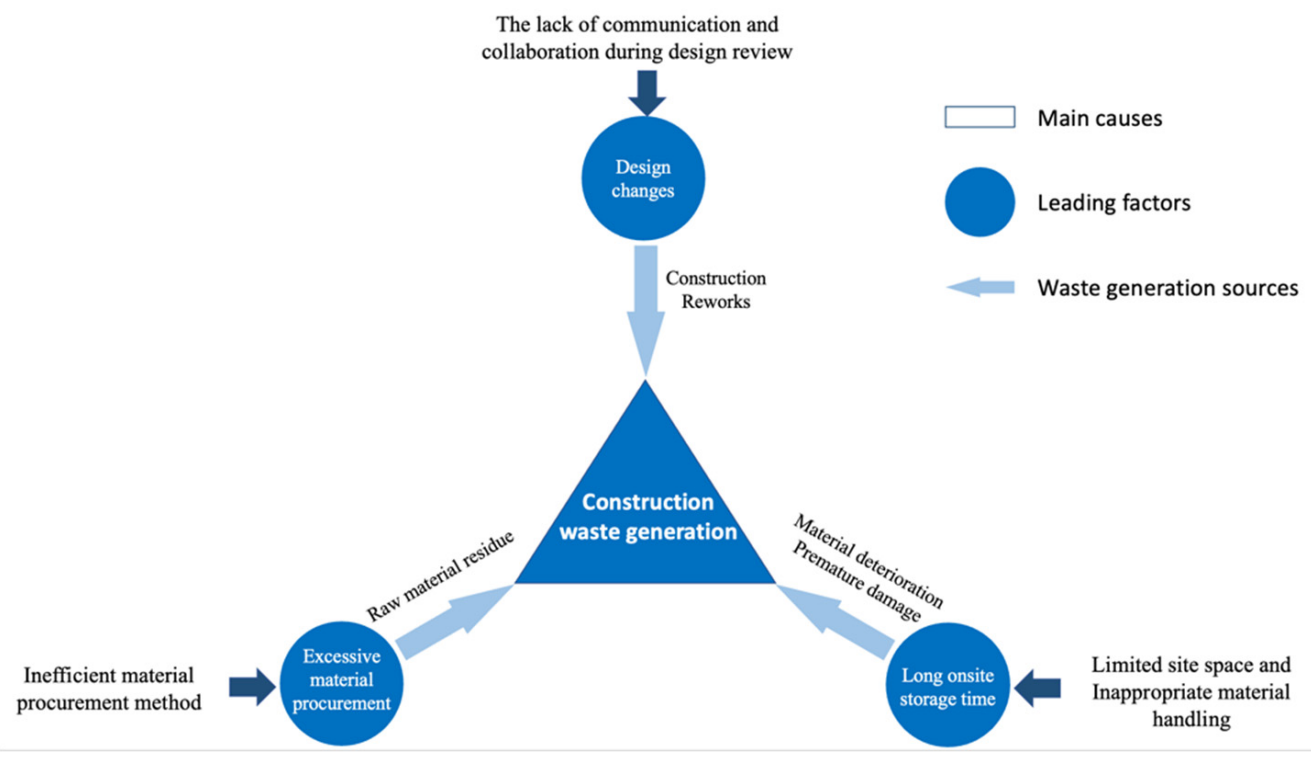

Figure 3. Primary causes and factors of preventable construction waste generation.

Another prevailing waste management strategy is recycling, which denotes the recovery of materials in a product. It often requires filtering and reprocessing for converting the waste materials into secondary products with a similar or lower quality [3]. Generally, onsite recycling is regarded as a more environmentally friendly C\&DWM approach than landfilling. However, the adoption of off-site recycling should consider the transport distance between the construction site and the recycling plant [23]. Although waste recycling can effectively preserve virgin materials and land resources, the decision-making regarding the C\&DWM strategy is ultimately profit-driven. Additionally, the economic viability of waste recycling is determined by manifold factors, such as the transportation distance, maturity level of the local recycling market, profitability of selling salvaged products, and regional recycling subsidy $[7,24,25]$.

Taken together, selecting the appropriate C\&DWM strategy for a specific project needs to evaluate technical and economic feasibility by considering the variations in project attributes and regional C\&DWM policies. In Section 3.2, we epitomize the main barriers to the effective implementation of C\&DWM and categorize them into three groups.

\subsection{Barriers to Implementing Effective CED Waste Management}

Australian construction industry practitioners are encountering heterogeneous obstacles when implementing C\&DWM. This study summarizes the barriers identified from the prior literature and groups them into three main categories as shown in Figure 4, which are (1) technology barriers, (2) policy barriers, and (3) human barriers. The interplay between these barriers across different categories increases the difficulty of tackling the issues independently. Restrictions and pressures imposed by the external stakeholders, including governments, and the general public will significantly affect the initiative and the decision-making of internal project stakeholders [26]. Thus, the barriers should be examined collectively to conceive of a comprehensive strategy. The following sections outline the existing barriers 


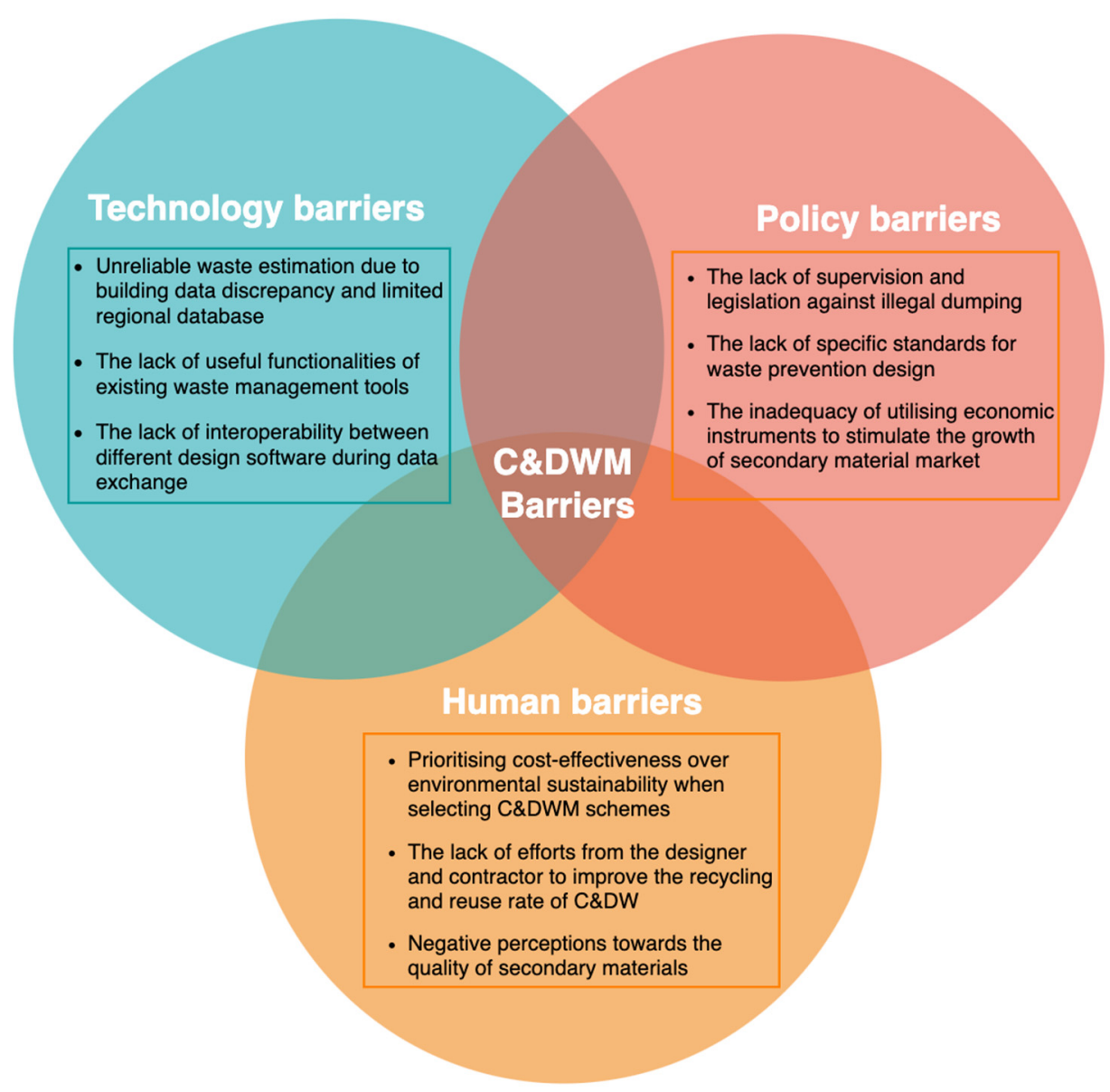

Figure 4. Barriers to effective C\&DWM.

\subsubsection{Technology Barriers}

In Australia, inadequate utilization of digital tools and advanced construction technologies hamper the efficiency of C\&DWM. Only two studies have focused on the role of technological innovation in empowering C\&DWM. A case study in Sydney conducted by Yazdani et al. demonstrates the capability of a simheuristic approach for C\&DW collection routing, wherein a hybrid Genetic Algorithm (GA) is developed to mitigate the uncertainty associated with previous deterministic vehicle routing models [27]. The other study aims to boost C\&DW market development by developing an intelligent advisory trading platform to help identify the potential recyclers and optimal sources and destinations for C\&DW [28]. In comparison, researchers from other regions paid closer attention to the use of innovative techniques for C\&DWM. For instance, Seror et al. [29] used a Geographic Information System (GIS) to identify potential C\&DW illegal dumping areas. Wu et al. [30] also integrated GIS into DWM for quantifying and visualizing demolition waste flow in both spatial and temporal dimensions. In Hong Kong, the government established a trip ticket system that can monitor the movement of waste-hauling trucks to supervise illegal dumping activities. Thus, contractors can be held accountable for illegal dumping. The quantity of C\&DW disposal can be determined accordingly [30].

Accurately estimating the quantities and types of C\&DW materials paves the way for efficient C\&DWM planning [31]. Across the building's lifecycle, perennial problems like poor data management and media discontinuities persist, thereby causing discrepancies between the original design drawings and the "as-is" building's condition. Thus, the reliability of waste estimation will be affected, thus impinging on the subsequent decision-making on waste bin arrangement and hauling truck planning. Furthermore, various design software and standards may be adopted during the design stage, which produces a vast amount of data and files in different formats. The lack of interoperability 
between waste management tools and mainstream design software hampers the data exchange efficiency.

Moreover, prevalent waste management tools, such as NETWaste and SMARTWaste, can only perform waste estimation based on the actual bill of quantity [31]. Besides, practical functionalities, such as Lifecycle Impact Assessment (LCA), deconstruction planning and multi-criteria decision analysis (MCDA) are not inherent in those waste management tools. Collectively, these technical problems make waste analytics dispensable and detached from the design process.

Furthermore, an effective and synergic decision-making mechanism requires highly engaged, risk-sharing collaboration among project stakeholders. However, stakeholders' collaboration is often impeded by disciplinary knowledge barriers [32]. To this end, BIM could serve as a multidisciplinary collaboration platform, which provides instant 3D visualization of design changes, seamless data exchange, and precise allocation of responsibilities for all project stakeholders jointly working toward an effective C\&DWM.

\subsubsection{Policy Barriers}

Because the level of economic development, technology advancement, and managerial capacity varies from region to region, formulating the most effective C\&DWM strategy requires multi-faceted considerations. To this end, policymakers are responsible for imposing adaptive waste charging schemes, legislation, and design standards at the regional level to regulate C\&DWM and promote the waste recycling business. However, in most developing countries, local governments merely raise the landfill levy in the hope of diverting C\&DW from landfills. Moreover, the waste disposal charging schemes based on material weight require further investigation and refinement, as different $C \& D W$ materials have distinctive environmental implications [33]. In contrast, the prominent policy barrier to effective C\&DWM in Australia is identified as "overregulation, tough acceptance criteria, and increased testing requirements for recycled materials" [34], thus hampering the development of local recycling businesses and C\&DW markets. Therefore, in the interest of ensuring the profitability of the waste recycling business while improving the price-competitiveness of the secondary materials market, key Australian C\&DW stakeholders underscore three main drivers for stimulating the growth of recycled C\&DW material markets, which include increasing the investment in technology and infrastructure, imposing consistent landfill levies, and guidelines for sustainable procurement [33].

Additionally, because of the discrepancy in landfill levies among different Australian jurisdictions, cross-jurisdiction waste movement persists, wherein some types of waste materials have to be transported interstate for a lower recycling or landfill cost [35]. South Australia acts as the waste recycling center of Australia, receiving over 172,500 tons of waste materials from other jurisdictions, wherein Victoria is the biggest interstate waste exporter, sending out 88,700 tons of waste to SA in the financial year of 2018-2019 [36]. Although cross-region C\&D waste movement can boost the waste trading and recycling market, the increasing transportation distance leads to excessive fuel consumption and air pollution. Essentially, Australian companies make up for the economic loss owing to the inconsistent policies at the cost of the environment. As such, the federal government should enact uniform legislation, subsidies, and landfill levies among jurisdictions to control the C\&DW cross-region movement.

On another note, the majority of the C\&DW generation can be attributed to design decision-making [37]. The absence of comprehensive design guidelines discourages designers from adopting waste prevention and prefabrication methods unless there is a design benchmark based on the environmental impacts and resource efficiency for achieving a higher sustainability rating [38]. For example, the enhancement and popularization of sustainability benchmarking and awarding systems, such as Green Star, is imperative, necessitating the establishment of specific reporting criteria and auditor requirements for waste data documentation. However, C\&DWM-related requirements in the current Green Star system are not sufficiently stringent, and the focal points lean toward regenerative 
environments [39]. Moreover, Udawatta et al. [40] reported that incorporating C\&DWM criteria into prequalification or tendering processes will motivate contractors to demonstrate their capabilities by formulating comprehensive C\&DWM schemes. In addition, Shooshtarian et al. (2021) [34] elicited the key stakeholders' perceptions toward waste regulations, policies, and schemes across Australian jurisdictions. The findings recommended adoption of shared responsibility by manufacturers for waste generation and imposition of guidelines to determine the acceptance criteria (e.g., contamination level) for waste reuse and recycling, thus valorising C\&DW materials. With this in mind, local governments should make a concerted effort to promulgate specialized designing-out, reusing, and recycling C\&DW guidelines and a holistic sustainability assessment framework at the national scale, thereby laying the foundation for conducting a systematic and rigorous assessment of the impacts of different C\&DWM schemes on the environment and the project's budget during the tendering process.

\subsubsection{Human Barriers}

Factors influencing the effective implementation of C\&DWM are associated with individual awareness, perceptions, attitudes, and behaviours and are universally recognized as human barriers $[40,41]$. Under profit-driven industry culture, the clients and contractors tend to prioritize project delivery time and budget reduction over waste minimization, indicating that cost control is their top priority when it comes to managing C\&DW [35]. Moreover, Zhao et al. (2021) [35] investigated the impact of legislation on the behaviour of the project's internal stakeholders and the influence of stakeholders' interactions on the outcomes of C\&DWM, identifying that negative attitudes, a lack of awareness, and a lack of commitment of construction practitioners remain the predominant factors hampering C\&DWM in Australia. In this context, contractors' and designers' attitudes and behaviours are heavily affected by the profitability of designing-out waste and waste recycling. Additionally, the inconsistent policies hamper the development of waste recycling markets and worsen the cost effectiveness of C\&DWM, thus contributing to the negative perception and attitude of industry stakeholders toward C\&DWM [35,42]. In addtion, several studies indicated that merely raising the landfill levy does not alleviate illegal dumping problems. Conversely, doing so increases the reoccurrence of illegal dumping activities and provokes a negative perception of C\&DWM $[43,44]$.

Moreover, construction industry practitioners tend to hold negative perceptions of secondary products' quality [3]. In Australia, crushed concrete aggregates are assigned to road-base and sub-base construction because of recycled concrete products' high porosity and absorption rate, making them unsuitable for structural applications [6].

Furthermore, Akinade et al. [45] reported that, owing to budget, time, and site space constraints, most construction and demolition contractors employ specialty waste management subcontractors to pick up the mixed C\&DW materials onsite and transfer them to their own waste recycling facilities for waste segregation, reuse, and recycling. Newaz et al. [46] investigated the critical factors affecting onsite C\&DWM in New South Wales, Australia, finding that contractors mainly focus on their core duty and shift the responsibility onto subcontractors for onsite C\&DW collection and segregation. Admittedly, conducting onsite waste segregation would require substantial managerial capacity and efforts from the contractors. Nevertheless, prompt waste segregation can significantly improve the quality of recycled aggregates by filtering out hazardous materials. Therefore, the economic benefits generated from the improved quality and value of recycled materials will triumph over the costs incurred in onsite waste segregation. Generally, the lack of initiative, environmental awareness, and managerial capacity of practitioners and their negative perceptions toward recycled products are the major human factors that impede the effective execution of C\&DWM. With that in mind, governments and companies should advocate the use of recyclable materials and raise the environmental awareness of stakeholders through sustainability-oriented education and training. The influence of education and training on stakeholders' attitudes and behaviours toward C\&DWM have been highlighted by 
various Australian studies [26,38,46]. For instance, Park and Tucker [26] accentuated that continuous professional development programs can enhance designers' willingness and ability to implement the low-waste design.

\subsection{BIM for CED Waste Management}

This section presents the BIM-based applications mentioned in the previous studies with the potential to facilitate C\&DWM. Figure 5 synthesizes the main BIM-based applications pertinent to each BIM dimension and the benefits brought by those applications in tackling C\&DW problems.

\begin{tabular}{|c|c|c|}
\hline BIM dimensions & BIM-based applications & Benefits to C\&D waste management \\
\hline \multirow{3}{*}{ 3D } & 3D coordination & $\begin{array}{l}\text { Minimising design errors and changes, } \\
\text { thus preventing reworks during construction }\end{array}$ \\
\hline & Clash detection & $\begin{array}{l}\text { Reducing waste generation by optimising the } \\
\text { material specification and component metrication }\end{array}$ \\
\hline & Material quantification & $\begin{array}{l}\text { Efficient material procurement to avoid } \\
\text { residue construction waste }\end{array}$ \\
\hline \multirow{3}{*}{ 4D } & \multirow{3}{*}{ Phase planning } & $\begin{array}{l}\text { Preventing material deterioration } \\
\text { and inappropriate material handling }\end{array}$ \\
\hline & & $\begin{array}{l}\text { Mitigating the risks associated with deconstruction } \\
\text { by stimulating the deconstruction process }\end{array}$ \\
\hline & & $\begin{array}{l}\text { Improving the efficiency of onsite waste collection } \\
\text { and transportation by integrating the waste } \\
\text { generation sequence with the project schedule }\end{array}$ \\
\hline 5D & Cost benefit analysis & $\begin{array}{l}\text { Optimising the cost efficiency by estimating the } \\
\text { costs incurred in waste management, and comparing } \\
\text { different waste management alternatives }\end{array}$ \\
\hline \multirow{2}{*}{ 6D } & $\begin{array}{l}\text { Recycling \& reuse } \\
\text { planning }\end{array}$ & $\begin{array}{l}\text { Reducing carbon emission and energy consumption } \\
\text { by identifying the onsite reuse opportunities }\end{array}$ \\
\hline & Sustainability analysis & $\begin{array}{l}\text { Improving the recycling and reuse rate and sustainability } \\
\text { performance by adopting more recyclable } \\
\text { materials and prefabricated components }\end{array}$ \\
\hline
\end{tabular}

Figure 5. Benefits provided by implementing BIM in C\&DWM practices.

\subsubsection{BIM-Based 3D Coordination and Material Quantification for Waste Minimization}

As previously noted, one of the primary sources of construction waste is the construction reworks caused by unexpected design modifications and errors $[47,48]$. Thus, collaborative design review is imperative for minimizing construction waste at its source. In this regard, BIM-based 3D coordination and clash detection can effectively minimize unexpected design changes by aiding the designers to identify and avoid unintended errors and spatial conflicts. In the case studies conducted by Won et al. [49], the results validated the effectiveness of BIM-based waste-preventive measures, such as clash detection, wherein $4.3 \%$ to $15.2 \%$ of construction waste generation is avoidable by implementing BIM-based design validation. Moreover, the volume of each waste stream can be automatically quantified using the BIM-based MQT method with minimal manual intervention and errors.

Kim et al. [50] developed a BIM-based framework for estimating demolition waste generation by type at the district level. The results showed that the accuracy of DW estimation heavily hinges on the level of details (LoD) of the BIM model and the comprehensiveness of the regional material database. Hence, their study only validates the applicability of the proposed framework for estimating the concrete waste stream in a specific region. Similarly, Bakchan et al. [27] proposed a BIM-based approach to quantify construction waste by subtracting the employed material quantities from the purchased material quantities. The purchasing records provided the quantities of purchased material, and the employed material quantities were obtained from the as-built BIM model using MQT. In the end, the researchers validated the accuracy of waste estimation results by comparing them with the ground-truth data documented in the hauling tickets. Nevertheless, the validation presumed all the construction waste generated in the case project was landfill-bound. Hence, further investigation is needed to account for the recycling/reuse scenarios. With 
3D coordination and material quantification competencies, designers can compare various design schemes based on the estimated waste output for each material type [51], thus improving the reuse/recycling rate and procurement efficiency by optimizing the material selection and dimensional coordination.

\subsubsection{BIM-Based 4D Planning for Efficient Deconstruction and Onsite Waste Collection and Segregation}

During the construction phase, leveraging BIM 4D phase planning enables just-intime delivery of materials, equipment, and labour force. As such, BIM-based construction planning can reduce the construction waste generation by avoiding premature material damage due to long periods of onsite storage and unnecessary material handling [11].

Furthermore, efficient site space utilization can streamline waste handling procedures by avoiding conflicts between onsite waste sorting and other construction activities, eventually leading to a higher recycling rate [14]. After the conventional demolition, building components turn into a mixture of inert and organic waste. Hence, screening out contaminated hazardous waste (e.g., mercury and insulating materials) and valuable recyclable waste, such as metals, during the onsite waste collection and sorting process is a prerequisite for distributing waste materials to their final destinations.

To that end, BIM-based 4D simulation and site space planning can facilitate the waste onsite collecting and sorting process by linking each building component with corresponding construction procedures in the project schedule. Thus, the quantities, accumulation sequence, and allocation of C\&DW can be predicted and visualized in the BIM model, thereby improving the effectiveness of C\&DWM planning for hauling truck arrangement and waste bin allocation. Guerra et al. [52] proposed a temporalbased approach using BIM-based phase planning to stimulate the construction waste accumulation sequence and identify potential onsite reuse opportunities. Nevertheless, the algorithms developed for onsite reuse planning are only valid for estimating the concrete and drywall waste streams. Future studies should develop a more holistic BIM-based reuse and recycling planning approach incorporating other major waste streams (e.g., masonry, gypsum, and wood).

Aside from identifying the onsite reuse opportunities, BIM can also improve the material recovery rate and the deconstruction efficiency by assisting designers in identifying waste-efficient design options. Akinade et al. [47] proposed a BIM-based framework called "BIM-DAS" for evaluating the level of difficulty of the deconstruction process at the design phase, which exemplifies the benefits of adopting prefabricated assemblies and demountable connections for improving the material recovery rate and deconstruction efficiency. Besides, the government and stakeholders can leverage this disassembly and deconstruction analytics system to appraise the compliance of building design with respect to SDG and indicators. Inadvertently, it will raise the practitioner's awareness and willingness to adopt selective deconstruction and designing-out waste strategies to promote the CE.

\subsubsection{BIM-Based Cost Analysis for Enhancing the Cost-Effectiveness of C\&DWM}

The cost analysis is imperative for achieving cost-efficient C\&DWM, in which the disposal cost and hauling activities require systematic estimation and monitoring [11]. To this end, Cheng and Ma [53] developed a BIM-based system that can estimate the demolition waste quantity and the DWM cost simultaneously by integrating the customizable waste indexes and cost parameters into the MQT procedure. However, the study did not combine BIM-based waste transportation scheduling with the cost prediction. As the disposal cost may fluctuate based on waste transportation planning, future research should investigate the influence of site space planning and scheduling on the transportation cost. Hamidi et al. [54] utilized BIM to perform the cost-benefit analysis to evaluate the economic viability of different waste management alternatives, in which the contractors can identify the optimal C\&DWM option by assessing the trade-off between the economic and environmental performance indicators. In the same vein, a BIM-based decision-aiding framework was developed for assessing the economic viability and environmental impacts of various 
deconstruction strategies [55]. The framework evaluates the cost, carbon footprint, and energy use by integrating customized deconstruction-related parameters into a typical BIM model. Zoghi and Kim [56] simulated and compared the economic performances between BIM-based construction waste management (CWM) and conventional ones based on quantitative economic benchmarks and a system dynamics approach. The cost-benefit analysis unveiled that BIM can reduce the cost incurred in CWM by $57 \%$, and the revenues gained from selling recyclable and reusable materials can roughly neutralize the deconstruction cost, even though adopting selective deconstruction is far more expensive than a conventional demolition strategy.

\subsubsection{BIM-Based LCA for Appraising the Sustainability Performance of C\&DWM}

Tackling sustainability problems like waste intensiveness and resource deficiency within the construction industry requires whole life cycle consideration [15]. In this context, life cycle assessment (LCA) is a reproducible and standardized methodology for assessing the environmental impacts of a product (i.e., buildings) from the cradle to the grave. Depending on the goal and scope defined by the user, the sustainability assessment of C\&DWM using LCA should address multiple impact categories and handle a vast amount of data generated from the impact assessment, which puts a question mark on the data interoperability between the LCA tool and other design software [57]. To this end, BIM has the potential to become a data repository, accumulating multidisciplinary information throughout the project life cycle, which can streamline the data flow between the central building information model and LCA tools. Jalaei et al. [58] embedded an add-in into the $\mathrm{BIM}$ tool to quantify the reductions in energy consumption and $\mathrm{CO}_{2}$ emission associated with C\&DWM generation prevented by BIM-based solutions. The results show that BIM can potentially decrease the total initial energy combustion and $\mathrm{CO}_{2}$ emission by up to $66.1 \%$ and $62.6 \%$, respectively.

Despite the potential benefits stemming from the adoption of BIM for conducting sustainability analysis at the design stage, certain methodological challenges persist for the full integration of BIM and the sustainability assessment tools. In previous attempts at BIM-LCA integration, BIM-based material quantification and life cycle impact assessment were typically performed in a separate manner, which required constant data exporting and importing between the BIM model and isolated assessment tools [59]. For instance, the bill of quantity (e.g., material quantities and types) derived from BIM and the environmental data provided by the LCA tool need to be integrated into a Microsoft Excel spreadsheet [60-62] or an external database [63,64] for the impact assessment. The applicability of those integration methods relies on the flexibility of the external database. Thus, the capabilities of BIM as an information repository to incorporate manifold LCA-related parameters and data are not fully capitalized.

Marrero et al. [65] point out that the optimal solution would be embedding the LCA parameters and data into the BIM model to perform the quantity take-off and impact assessment concurrently within the BIM environment. Notwithstanding, the BIM-LCA integration is time-consuming during the model construction phase, as the LCA data needs to be linked with each BIM component manually. If the designers update the BIM model with the addition of new components, related LCA data needs to be modified and integrated.

Thus, to evaluate the sustainability performance of C\&DWM by utilizing LCA methodologies and BIM technology, the C\&DWM-related parameters for quantifying the environmental impacts of C\&DW should be integrated into the BIM model by enriching the properties of the Industry Foundation Class (IFC) model.

\subsubsection{BIM-Based Collaboration for Tackling Managerial and Cultural Barriers}

The emergence of BIM technology has provided the AEC industry with an IPD approach for information management, in which building information can be seamlessly conveyed and exchanged on an integrated platform throughout the project life cycle. It 
allows for transparent information exchange, synchronous access, and modification to the central BIM model by all the project team members. Therefore, this feature enables allocating and monitoring responsibilities among stakeholders to avoid conflicts and shifting responsibilities [65,66]. Moreover, BIM can effectively address the lack of interoperability among different design software, thereby enabling efficient collaboration among the designers. From the construction management standpoint, leveraging BIM-based collaboration for task harmonization can avoid duplication of efforts, thus eliminating non-value-added works $[48,65]$.

Despite the potential benefits outlined above, BIM adoption in the Australian AEC industry has been stalled, as the usage rates of BIM capabilities such as $4 \mathrm{D}$ construction and maintenance scheduling (33.3\%) and 6D sustainability analysis (11.1\%) are low compared to North America (54.5\% and $72.7 \%$, respectively) [67]. Barriers causing the stagnation in BIM adoption are manifold, including ambiguity in data ownership, lack of clients/market demands and incentives, limited BIM library and dataset, and the extra efforts required for BIM development [68]. The following section will investigate the technical limitations associated with improving BIM adoption in DWM practices.

\section{Discussion}

\subsection{Challenges of Adopting BIM in DWM for Existing Buildings}

Extant studies show evidence that the majority of C\&DW arises from building demolition. Thus, the resource and energy efficiency of the AEC industry hinge on the effectiveness of DWM [69]. Nevertheless, the primary focus in previous research is on enhancing CWM at the design and construction stage [11,15,31,45,70,71]. Contrarily, BIM implementation in DWM is rarely getting traction, owing to manifold limitations. This is because leveraging BIM applications for improving DWM is founded on an as-is BIM model, which is an object-oriented, digital embodiment of the existing building. All the relevant information across the building's entire life cycle from design to demolition, including geometric, material properties, project schedule, and cost information, is epitomized. Albeit prior studies constructed the as-is BIM models based on the original design drawings to aid DWM in demolition waste quantification [49], hauling truck planning, and disposal cost estimation [53], they omitted the fact that those original design drawings are typically inconsistent with the actual condition of existing buildings. Therefore, the practicability of those BIM-based applications will be hindered by misleading outdated information.

As such, the reconstruction of the as-is BIM using the data collected from building surveying is a prerequisite for BIM-based DWM. Creating the as-is BIMs from scratch is often referred to as "Scan-to-BIM," which comprises three main phases, encompassing (1) point cloud data acquisition, (2) point clouds segmentation and object recognition, and (3) BIM modelling. The process of BIM reconstruction is tedious and time-consuming. Due to limited budget and time, practitioners are reluctant to adopt BIM in DWM practices without up-to-date building documentation guiding the process. Furthermore, predominating issues like the lack of BIM-compliant DWM functionalities and interoperability between BIM and waste management tools also stand out as significant challenges to be addressed in future studies.

\subsubsection{Constructing the BIM Models for Existing Buildings without Up-to-Date Drawings}

Regarding the information capturing of existing facilities, selecting suitable methods to collect as-is building data provides accurate inputs for creating building stock models containing essential DWM-related data, such as geometric size and material composition of building elements. Accurately forecasting the volume/weight of each DW material is a prerequisite for implementing selective deconstruction and optimized waste stream routing [72]. Thus, it is desirable to capture the geometric dimensions of main building components and their material properties. In recent years, technological advancements of onsite surveying techniques have enabled BIM applications for construction progress monitoring, quality assessment, and facility management. The most advanced and prevailing 
building information capturing methods fixate on 3D point cloud data acquisition, which can be categorized into range-based, image-based, and integrated methods.

Terrestrial Laser Scanning (TLS) is a high-precision range-based technique that captures geometric information and spatial relationships of building elements. It can effectively capture high-resolution point clouds with a relatively short duration. However, the quality of TLS often suffers from clutters and occlusions in the building's indoor environment and highly non-reflective surfaces [73]. Moreover, due to the high cost and fragility of equipment, along with the lack of trained operators and portability, adopting TLS for building data acquisition may not apply to all the scenarios. Additionally, point clouds generated by laser scanners need to be filtered and downsized to remove the noises and outliers before conducting subsequential procedures [74]. It is hard to justify the upfront costs and the time invested in the building data acquisition by the benefits that stem from empowering DWM with BIM.

Therefore, an evaluation standard must be developed to assess the trade-off between the BIM reliability and the point cloud capturing costs. Compared to TLS, image-based photogrammetry is a more economical approach, which captures the geometric and material information of building elements with a portable RGB-D camera. With a collection of overlapping images, a 3D point cloud model of the target building can be created by using image-based 3D reconstruction techniques, such as structure from motion. Still, it takes extra effort to process images captured from multiple views to create a 3D geometric representation of a specific scene [75].

Bhatla et al. [76] investigated the combined use of photogrammetry and computer vision for enabling automated $3 \mathrm{D}$ reconstruction of civil infrastructure and evaluated the performance of existing algorithms for raw sensor data processing and 3D reconstruction. The challenges associated with capturing building existing conditions with photogrammetry techniques are identified accordingly and classified into two categories: (1) technological gaps and (2) practical constraints. The technological gaps include (1) detecting and matching distinctive visual features in indoor environments, (2) the ambiguity in estimating the scale factor caused by the translation of camera poses, (3) the fact that the quality and repeatability of image-based 3D reconstruction are unpredictable as the illumination condition fluctuates throughout the day, (4) time-consuming pairwise feature matching and bundle adjustment, (5) the lack of standard benchmarks for comprehensive quantitative assessment of image-based reconstruction algorithm's performance, and (6) the labour-intensive and tedious process of converting raw point cloud data into a semantic 3D model. In the hopes of future technological advancements, the practicability and efficiency of reconstructing semantic BIM models using photogrammetry techniques can be improved. In reality, however, several practical constraints are inevitable, which encompass (1) occlusions causing the loss of information in images, (2) inaccessibility to particular site locations for desirable shooting, (3) the fact that visibility of objects may be affected by the insufficient lighting conditions, and (4) the trade-off between expanding the shooting scope and enhancing the detail of the image.

Estimating DW outputs requires accurate geometric (e.g., dimensions) and nongeometric information (e.g., material type, bulking factor, and density) for each building element. However, due to the budget and time constraints, hidden utilities such as Mechanical, electrical, and plumbing and the reinforcement bars are typically excluded from the BIM modelling of existing facilities. Omitting the concealed elements will affect the LoD of the BIM model, thus inevitably leading to inaccuracy in DW estimation (e.g., overestimation of the concrete waste stream).

Furthermore, creating a semantically rich 3D representation of the target building is tediously time-consuming, especially for existing buildings whose original design drawings are lost or inconsistent with the actual building conditions. Researchers have devoted themselves to developing intelligent object recognition algorithms to automatize the point cloud segmentation and semantic modelling process. Still, all the previous attempts ended up with either semi-automated or partial BIM model reconstruction. 
For example, Xiong et al. [77] developed a context-based modelling algorithm to automatically identify and model the main structural components (e.g., walls, floors, ceilings) in cluttered scenes. However, this method failed to recognize the more complex building components with irregular shapes. Similarly, Ge et al. [78] achieved automated $3 \mathrm{D}$ reconstruction of main building components (e.g., doors, wallsl and windows) via an image-based method. However, reconstructing randomly located small-size components, such as light fixtures, meant the furniture still required frequent manual intervention. Hence, those Scan-to-BIM methods can be classified as partial BIM reconstruction as they failed to resurrect the complete digital model of the target building.

Other previous attempts fall into another category called the "semi-automated" approach. For example, Jung et al. [79] were able to downsize the point cloud data without sacrificing the data accuracy. This semi-automated method streamlines the process of creating the as-is BIMs for complex structures. Hong et al. [80] modelled the wireframe of the structure using the constrained least-squares method. Nevertheless, the modelling of doors and windows still requires manual operation to achieve detailed 3D reconstruction. Volk et al. [81] developed an innovative system that captures the point cloud data of the building's interior using Microsoft Kinect sensors. The built-in software modules can automatically process and convert the data into a semantically rich 3D BIM model with building inventory information in a real-time fashion for deconstruction planning. However, the robustness of the algorithms requires further enhancement to improve the accuracy of data interpretation. Collectively, these studies reveal that inefficient data capturing, error-prone object recognition, and semantic labelling are the significant obstacles to the broader implementation of BIM for DWM.

\subsubsection{Engaging BIM-Based DWM with the Deconstruction Planning Process}

There are two categories of expert functionalities. The first is BIM's built-in functions like clash detection, schedule planning, and cost estimation. The second is in the form of independent expert applications. The former is typically applied in building design, material procurement, and construction management, whereas BIM-based applications that concentrate on deconstruction planning and DWM at the end-of-life phase are rare. The usability of independent expert applications is hampered by data interoperability issues.

The most common functionality of commercial waste management tools is predicting the C\&D waste output. Waste prediction tools such as SMARTWaste, Designing-out Waste Tool for Buildings (DoWT-B), and Net Waste Tool can perform waste quantity forecasts by analysing building design specifications and the bill of quantity. However, none of the above waste prediction tools are BIM-compliant [30]. Thus, integrating the waste prediction functionality of C\&DWM tools into the BIM-based design software has become the major challenge to synchronizing real-time waste analytics with the design and planning process. By improving the software interoperability among C\&DWM tools and BIM software, waste analytics applications enhanced by the BIM features will be generalized in the conventional construction project design.

The recent development in BIM functionality and application research is trending toward sustainability analysis aspects, in which greenhouse gases emissions $[82,83]$ and energy simulation $[73,84]$ are among the prevalent applications for the appraisal of building's sustainability performance at the construction and operation phase. However, there are no waste management tools or BIM-compliant plug-ins available for evaluating the sustainability performance of DWM at the building's end-of-life stage.

BIM features in different phases of the building's life cycle are linked with a central platform through the Information Delivery Manual and Model View Definitions (MDV) to provide detailed specifications of the relevant information and to facilitate data exchange using IFC or the Extensible Markup Language (XML) schema. In comparison, using different data structures and exchange schemas to transfer interdisciplinary data across different programs will raise concerns over data readability, interoperability, and ambiguities [85]. 
Moreover, the semantic data which needs to be incorporated into the BIM model will increase progressively throughout the project's lifecycle, thus causing administration and communication issues involving individual information and wide-ranging professional languages [72]. Several researchers have reported interoperability issues between various BIM tools applied in different domains, such as Facility Management [86,87], sustainability analysis [88], and deconstruction/waste management [89]. Soust-Verdaguer et al. [57] attribute the interoperability issues to the lack of open-data schemas and uniform data structure that enables automatic data exchange without manual manipulation and errors. Tackling software interoperability issues between waste management tools and BIM software will expand the BIM-based applications into the waste management analytics domain and vice versa.

\subsection{Research Agenda}

This section presents recommended future research directions considering the technical problems associated with building data capturing, data processing, and waste management software interoperability. Figure 6 outlines future research directions for empowering BIM-oriented DWM.

\section{Research agenda}

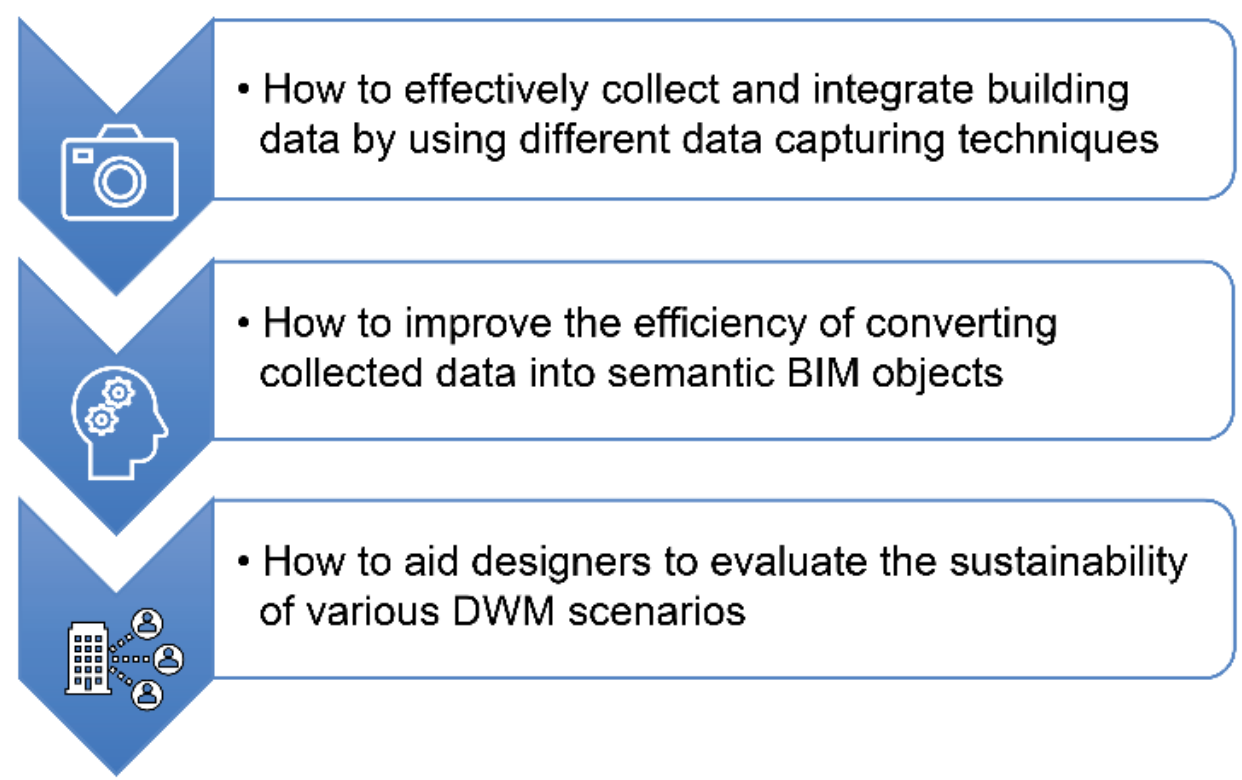

Figure 6. Research agenda on leveraging BIM technology for C\&DWM.

\subsubsection{How to Effectively Collect and Integrate Building Data by Using Different Data} Capturing Techniques

As previously stated, there is no unanimously preferred building data capturing technique, as the adoption of data capture techniques should account for various factors such as project scale, site conditions, schedule, and budget constraints. To this end, Barki et al. [90] advocate for the combined use of different data capture methods whenever possible to overcome their inherent limitations. Recent studies have proposed a data capture framework that combines TLS with photogrammetry to capture high-resolution geometric information and highly textured material information, respectively. Thus, the combination of laser scanning and photogrammetry can effectively reduce the redundancy and ambiguity in captured data without compromising the quality [91,92]. Nevertheless, the deployment and calibration of different surveying equipment in complicated building interior scenes require systematic guidelines for a more adaptable data acquisition process. For example, employing multiple camera sensor networks might be able to solve the occlusion issues 
associated with indoor scenes [76]. Moreover, controlling leading factors like image setting, camera internal parameters, and processing algorithms can effectively minimize discrepancies between the reconstructed 3D models and the actual objects by reducing the inaccurate reasoning and mismatching errors occurring in object recognition [75].

To improve the LoD of the BIM model, concealed building elements like reinforcement bars and underground utilities should not be neglected during the data acquisition. However, neither TLS nor photogrammetry methods can penetrate the surface of structural components. To this end, employing Ground-Penetrating Radars (GPR) is a practical solution to identifying the concealed building elements, such as rebars, wires, and pipes [93]. Conversely, the more the data-capturing techniques are being employed, the higher is the equipment cost, and operation skills along with more convoluted data integration and processing are required. Future studies should concentrate on more efficiently extracting and integrating the building data obtained from different sources (e.g., TLS scan, GPR profiles, and images).

\subsubsection{How to Improve the Efficiency of Converting Collected Data into Semantic BIM Objects}

Realizing BIM-based DWM often requires automated reverse engineering methods to convert the as-is BIMs from point cloud data [94]. Consequently, laborious procedures like data pre-processing, segmentation, object recognition, and semantic labelling are mostly inevitable. Under such circumstances, the development of robust machine learning algorithms is indispensable for minimizing manual intervention during outlier removal, noise filtering, voxelization, and point cloud registration. With the advancement and integration of machine learning techniques, the goal of enabling automated "Scan-to-BIM" conversion will become attainable in the foreseeable future. Barki et al. [90] dispute that converting 2D drawings into a semantic 3D BIM model is a more economical and efficient compared to "Scan-to-BIM", albeit the information provided by CAD drawings most ideally can reflect the as-built condition of the building.

To account for changes occurred during the operation and renovation stage, future studies should address the difficulty of automatic identification of the discrepancies between the as-built and as-is condition. Then, the updated information still needs to be manually imported into the existing BIM model in the form of 3D point cloud data. For planar objects like walls, slabs, and rectangular columns, previous research employs RANdom Sample Consensus (RANSAC) algorithms to automatically detect the planar objects from 3D point clouds and incorporate them into the existing BIM model [79,80,95]. However, the recognition and extraction of semantic information, such as material type, still require manual inspection and matching from the trained operator. Future research should consider exploiting machine learning algorithms to automatically extract the material information by matching the material type with features like colours and textures.

\subsubsection{How to Aid Designers to Evaluate the Sustainability of Various DWM Scenarios}

In terms of integrating waste management tools into the actual design process, there is an urgent need for improving data interoperability and multidisciplinary collaboration by accommodating essential waste management functionalities into an integrated BIM platform. Regarding the interoperability issues and information loss during data exchange between different design platforms, the AEC industry must be synchronized in developing and managing data formats and exchange protocols [85]. Wong et al. [87] found evidence that current BIM open standards, such as IFC and Construction Operations Building Information Exchange (COBie), are not versatile enough to accommodate the data entities, element properties, and parameters required for integrating the LCA functionality into a BIM-based environment.

Another research trend that needs advocating in the future is identifying specific information (e.g., properties inherent in BIM objects) required for simulating the life cycle impacts of various DWM scenarios within the BIM-based platform. In light of this, Santos et al. [96] suggested that 137 IFC properties need to be incorporated for the compre- 
hensive assessment of the environmental and economic impacts at the building's end-of-life phase. In addition, there is an absence of guidelines and standards for determining how DWM-related information should be structured and incorporated into the BIM objects, depending on the project's LoD requirements [97]. Future studies should enrich the existing BIM libraries, open standards, and data specifications to enable BIM-based LCA and deconstruction simulation for the DWM planning. Jayasinghe et al. [8] developed a BIM-based online materials and components $(\mathrm{M} \& \mathrm{C})$ bank for storing essential information and parameters of various building elements, including structural, chemical, thermal, and other properties. All the data are transferred from the Revit BIM model to the web-based M\&C bank using a Dynamo script. As such, this creates an easily accessible platform to retrieve the information from the BIM model for estimating the quantities and the allocations of reusable, recyclable, and hazardous materials in the building, which pave the way for conducting sustainability analysis and deconstruction risk assessment. However, the applicability of the BIM-based M\&C bank will be influenced by the precision of the BIM model and the availability of the regional database, which is limited to Luxembourg and Europe regions. The availability of regional databases that provide reliable LCA data plays a crucial role in the robustness of BIM-based sustainability assessment. This opinion is supported by the recent study of [65], in which they imported the LCA data into the BIM objects to assess several ecological criteria, such as carbon footprint and embodied energy, by decomposing the building elements into unitary construction materials or units. Thus, a variety of resources being consumed and the related ecological impacts during the demolition and waste treatment process can be quantified within the BIM-based environment. To expand the application of this approach to assessing the sustainability criteria regarding DWM, generic databases containing the LCA data related to demolition and waste recycling works, such as engine power output and conversion factor, should be established.

Further, among all the existing waste management tools equipped with waste management functionalities, DRWE [53] and BIM-DAS [47] are the only BIM-compliant tools designed for waste management applications. This situation calls for developing more versatile BIM-compliant waste management tools to synchronize waste analytics and waste management planning with other design procedures, thereby enhancing the engagement of waste management tools within the design and planning process. For instance, Carvalho et al. [98] exploited BIM to automate and integrate the process of LCA and building sustainability assessment, which enabled a more efficient evaluation of various sustainability criteria, owing to its interoperability capabilities and multidisciplinary data accessibility. However, the evaluation criteria and data stored in the databases of LCA and sustainability assessment tools are not consistent, thus confusing the evaluation process, and the direct outputs generated from those two methods are not comparable. Therefore, matching the material databases between LCA and sustainability assessment tools (e.g., Green Star, LEED) is a pivotal factor that will streamline the evaluation process and extend the application of sustainability analysis to the DWM sector.

To conclude, creating the BIM of existing buildings with adequate LoD is beneficial to systematically facilitating the DWM practices, such as onsite waste sorting, budget estimation, and waste transportation. In Figure 7, a visual map elucidates the procedures of integrating BIM into DWM. Moreover, the applications and benefits provided by BIM during the DWM process are highlighted. 


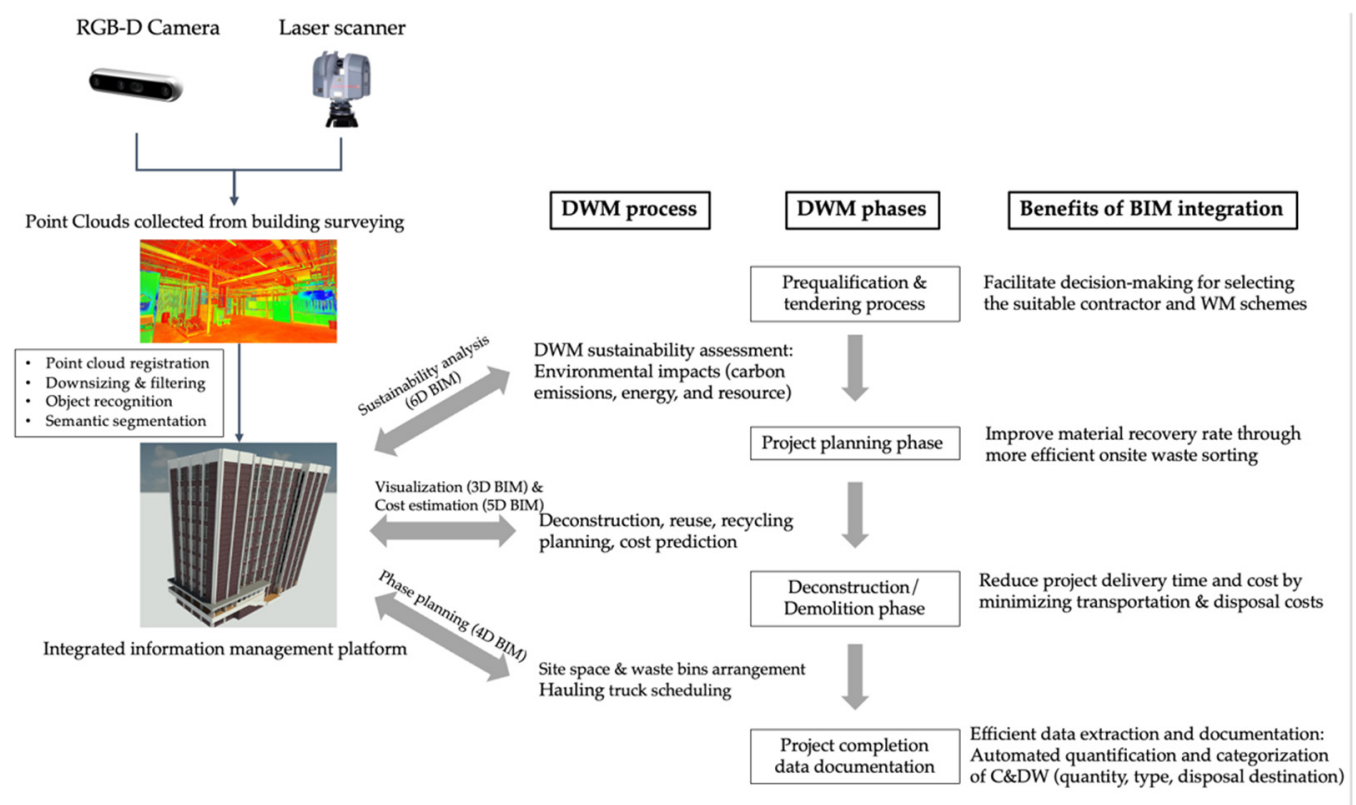

Figure 7. Visual process map of BIM integration in demolition waste management process.

\section{Conclusions}

Due to the accelerated urban development, the amount of C\&D waste disposed to landfills has grown exponentially over the years. Policymakers and industry practitioners must improve their awareness and efforts to promote and implement effective C\&DWM. Albeit, the emergence of BIM technology provides new opportunities to reduce construction waste generation and project costs by enhancing the quality of design and construction management with inherent capabilities like MQT, spatial conflict analysis, and multidisciplinary data communications. However, few studies have focused on how to more effectively manage demolition waste generated from existing buildings with the aid of BIM applications. With this in mind, this study investigated the existing challenges in adopting BIM in the DWM domain and proposed future research directions in response to those challenges. By systematically reviewing 98 academic publications, we identified the main barriers hindering the extensive adoption of BIM in the DWM domain:

- The inefficient building data acquisition and integration process due to limitations of individual data-capturing techniques and the incompatibility of different data sources

- The error-prone, time-consuming object recognition and semantic labelling process for converting point clouds into BIMs with adequate $\mathrm{LoD}$ for DWM applications

- Existing waste management software and inherent waste analytic functionalities are not compatible with BIM, thus making them detached from the BIM-based design process

In response to those challenges, this research proposed a research agenda consisting of three major items:

- Improving the efficiency and quality of data acquisition by deploying various datacapturing tools

- Realizing an automated conversion from point cloud to BIM by identifying the best combinations of algorithms for object recognition and semantic labelling

- Extending BIM-based sustainability analysis to the DWM domain by developing extended IFC data schema and comprehensive material databases

Overall, this study contributes to the body of knowledge by identifying the research gaps hindering the adoption of BIM for C\&DWM and proposes future directions for the integration of BIM in DWM. Moreover, this study elucidates the prevalent issues in current Australian C\&DWM practices and reveals the flaws in policies leading to interstate waste transportation and the premature C\&DWM sustainability benchmarking system. Despite 
the contribution of this study, some limitations were not fully addressed in this paper. First, it did not propose any specific technological solutions or policy recommendations to availing C\&DWM in Australia. Besides, this study mainly focused on identifying the challenges and investigating possible solutions to the implantation of BIM in DWM practices. Future studies should adopt these findings as the framework to validate the advantages of BIM in improving the cost effectiveness and resource efficiency of the real-life DWM projects.

Author Contributions: D.H.: Conceptualization, methodology, data curation, and writing—original draft, revision, and editing; M.K.: Conceptualization, supervision, and writing-review and editing; A.R.: Supervision, writing-review and editing. All authors have read and agreed to the published version of the manuscript.

Funding: This research received no external funding. The University of Melbourne provided the Melbourne Research Scholarship (MRS) for conducting this research.

Institutional Review Board Statement: Not applicable.

Informed Consent Statement: Not applicable.

Data Availability Statement: Not applicable.

Conflicts of Interest: The authors declare no conflict of interest.

\section{References}

1. Shen, L.Y.; Tam, V.W.Y.; Tam, C.M.; Drew, D. Mapping Approach for Examining Waste Management on Construction Sites. J. Constr. Eng. Manag. 2004, 130, 472-481. [CrossRef]

2. Yeheyis, M.; Hewage, K.; Alam, M.S.; Eskicioglu, C.; Sadiq, R. An Overview of Construction and Demolition Waste Management in Canada: A Lifecycle Analysis Approach to Sustainability. Clean Technol. Environ. Policy 2013, 15, 81-91. [CrossRef]

3. Ghisellini, P.; Ripa, M.; Ulgiati, S. Exploring Environmental and Economic Costs and Benefits of a Circular Economy Approach to the Construction and Demolition Sector. A Literature Review. J. Clean. Prod. 2018, 178, 618-643. [CrossRef]

4. Pickin, J.; Randell, P. Australian National Waste Report 2020. In Australian Government: Department of the Environment and Energy 2020; Blue Environment: Docklands, VIC, Australia, 2020.

5. Wang, J.; Wu, H.; Duan, H.; Zillante, G.; Zuo, J.; Yuan, H. Combining Life Cycle Assessment and Building Information Modelling to Account for Carbon Emission of Building Demolition Waste: A Case Study. J. Clean. Prod. 2018, 172, 3154-3166. [CrossRef]

6. Tam, V.W.Y. Comparing the Implementation of Concrete Recycling in the Australian and Japanese Construction Industries. J. Clean. Prod. 2009, 17, 688-702. [CrossRef]

7. Zhao, W.; Leeftink, R.B.; Rotter, V.S. Evaluation of the Economic Feasibility for the Recycling of Construction and Demolition Waste in China-The Case of Chongqing. Resour. Conserv. Recycl. 2010, 54, 377-389. [CrossRef]

8. Jayasinghe, L.B.; Waldmann, D. Development of a Bim-Based Web Tool as a Material and Component Bank for a Sustainable Construction Industry. Sustainability 2020, 12, 1766. [CrossRef]

9. Poon, C.S.; Yu, A.T.W.; Ng, L.H. On-Site Sorting of Construction and Demolition Waste in Hong Kong. Resour. Conserv. Recy. 2001, 32, 157-172. [CrossRef]

10. Cochran, K.M.; Townsend, T.G. Estimating Construction and Demolition Debris Generation Using a Materials Flow Analysis Approach. Waste Manag. 2010, 30, 2247-2254. [CrossRef] [PubMed]

11. Won, J.; Cheng, J.C.P. Identifying Potential Opportunities of Building Information Modeling for Construction and Demolition Waste Management and Minimization. Autom. Constr. 2017, 79, 3-18. [CrossRef]

12. Faniran, O.O.; Caban, G. Minimizing Waste on Construction Project Sites. Eng. Constr. Archit. Manag. 1998, 5, 182-188. [CrossRef]

13. Yuan, H.P.; Shen, L.Y.; Hao, J.J.L.; Lu, W.S. A Model for Cost-Benefit Analysis of Construction and Demolition Waste Management Throughout the Waste Chain. Resour. Conserv. Recycl. 2011, 55, 604-612. [CrossRef]

14. Wang, J.; Yuan, H.; Kang, X.; Lu, W. Critical Success Factors for On-Site Sorting of Construction Waste: A China Study. Resour. Conserv. Recycl. 2010, 54, 931-936. [CrossRef]

15. Ajayi, S.O.; Oyedele, L.O.; Bilal, M.; Akinade, O.O.; Alaka, H.A.; Owolabi, H.A.; Kadiri, K.O. Waste Effectiveness of the Construction Industry: Understanding the Impediments and Requisites for Improvements. Resour. Conserv. Recycl. 2015, 102, 101-112. [CrossRef]

16. Osmani, M. Construction Waste Minimization in the UK: Current Pressures for Change and Approaches. Procedia Soc. Behav. Sci. 2012, 40, 37-40. [CrossRef]

17. Jaillon, L.; Poon, C.S.; Chiang, Y.H. Quantifying the Waste Reduction Potential of Using Prefabrication in Building Construction in Hong Kong. Waste Manag. 2009, 29, 309-320. [CrossRef] [PubMed]

18. Tam, V.W.Y.; Tam, C.M.; Zeng, S.X.; Ng, W.C.Y. Towards Adoption of Prefabrication in Construction. Build. Environ. 2007, 42, 3642-3654. [CrossRef] 
19. Chen, J.; Su, Y.; Si, H.; Chen, J. Managerial Areas of Construction and Demolition Waste: A Scientometric Review. Int. J. Environ. Res. Public Health 2018, 15, 2350. [CrossRef]

20. Lu, W.; Yuan, H. Exploring Critical Success Factors for Waste Management in Construction Projects of China. Resour. Conserv. Recy. 2010, 55, 201-208. [CrossRef]

21. Gálvez-Martos, J.L.; Styles, D.; Schoenberger, H.; Zeschmar-Lahl, B. Construction and Demolition Waste Best Management Practice in Europe. Resour. Conserv. Recycl. 2018, 136, 166-178. [CrossRef]

22. Akinade, O.; Oyedele, L.; Oyedele, A.; Davila Delgado, J.M.; Bilal, M.; Akanbi, L.; Ajayi, A.; Owolabi, H. Design for Deconstruction Using a Circular Economy Approach: Barriers and Strategies for Improvement. Prod. Plan. Control. 2019, 31, 829-840. [CrossRef]

23. Bovea, M.D.; Powell, J.C. Developments in Life Cycle Assessment Applied to Evaluate the Environmental Performance of Construction and Demolition Wastes. Waste Manag. 2016, 50, 151-172. [CrossRef] [PubMed]

24. Duran, X.; Lenihan, H.; O'Regan, B. A Model for Assessing the Economic Viability of Construction and Demolition Waste Recycling - The Case of Ireland. Resour. Conserv. Recycl. 2006, 46, 302-320. [CrossRef]

25. Wu, H.; Duan, H.; Wang, J.; Wang, T.; Wang, X. Quantification of Carbon Emission of Construction Waste by Using Streamlined LCA: A Case Study of Shenzhen, China. J. Mater. Cycles Waste Manag. 2015, 17, 637-645. [CrossRef]

26. Park, J.; Tucker, R. Overcoming Barriers to the Reuse of Construction Waste Material in Australia: A Review of the Literature. Int. J. Constr. Manag. 2017, 17, 228-237. [CrossRef]

27. Yazdani, M.; Kabirifar, K.; Frimpong, B.E.; Shariati, M.; Mirmozaffari, M.; Boskabadi, A. Improving construction and demolition waste collection service in an urban area using a simheuristic approach: A case study in Sydney. Aust. J. Clean. Prod. 2021, 280. [CrossRef]

28. Shooshtarian, S.; Maqsood, T.; Wong, P.S.P.; Yang, R.J.; Khalfan, M. Review of waste strategy documents in Australia: Analysis of strategies for construction and demolition waste. Int. J. Environ. Technol. Manag. 2020, 23, 1-21. [CrossRef]

29. Seror, N.; Portnov, B.A. Identifying Areas Under Potential Risk of Illegal Construction and Demolition Waste Dumping Using GIS Tools. Waste Manag. 2018, 75, 22-29. [CrossRef]

30. Wu, H.; Wang, J.; Duan, H.; Ouyang, L.; Huang, W.; Zuo, J. An Innovative Approach to Managing Demolition Waste via GIS (Geographic Information System): A Case Study in Shenzhen City, China. J. Clean. Prod. 2016, 112, 494-503. [CrossRef]

31. Bakchan, A.; Faust, K.M.; Leite, F. Seven-Dimensional Automated Construction Waste Quantification and Management Framework: Integration with Project and Site Planning. Resour. Conserv. Recycl. 2019, 146, 462-474. [CrossRef]

32. Udawatta, N.; Zuo, J.; Chiveralls, K.; Zillante, G. Attitudinal and Behavioural Approaches to Improving Waste Management on Construction Projects in Australia: Benefits and Limitations. Int. J. Constr. Manag. 2015, 15, 137-147. [CrossRef]

33. Shooshtarian, S.; Maqsood, T.; Wong, P.S.P.; Khalfan, M.; Yang, R.J. Market development for construction and demolition waste stream in Australia. J. Constr. Eng. Manag. Innov. 2020, 3, 220-231. [CrossRef]

34. Shooshtarian, S.; Caldera, S.; Maqsood, T.; Ryley, T.; Khalfan, M. An investigation into challenges and opportunities in the Australian construction and demolition waste management system. Eng. Constr. Archit. Manag. 2021. [CrossRef]

35. Zhao, X.; Webber, R.; Kalutara, P.; Browne, W.; Pienaar, J. Construction and Demolition Waste Management in Australia: A Mini-Review. Waste Manag. Res. 2021. [CrossRef]

36. Wu, H.; Zuo, J.; Yuan, H.; Zillante, G.; Wang, J. Cross-Regional Mobility of Construction and Demolition Waste in Australia: An Exploratory Study. Resour. Conserv. Recycl. 2020, 156, 104710. [CrossRef]

37. Poon, C.S.; Yu, A.T.W.; See, S.C.; Cheung, E. Minimizing Demolition Wastes in Hong Kong Public Housing Projects. Constr. Manag. Econ. 2004, 22, 799-805. [CrossRef]

38. Udawatta, N.; Zuo, J.; Chiveralls, K.; Zillante, G. Improving Waste Management in Construction Projects: An Australian Study. Resour. Conserv. Recycl. 2015, 101, 73-83. [CrossRef]

39. Udawatta, N.; Zuo, J.; Chiveralls, K.; Zillante, G. From Green Buildings to Living Buildings? Rating Schemes and Waste Management Practices in Australian Educational Buildings. Eng. Constr. Archit. Manag. 2021, 28, 1278-1294. [CrossRef]

40. Udawatta, N.; Zuo, J.; Chiveralls, K.; Yuan, H.; George, Z.; Elmualim, A. Major Factors Impeding the Implementation of Waste Management in Australian Construction Projects. J. Green Build. 2018, 13, 101-121. [CrossRef]

41. Akinade, O.O.; Oyedele, L.O.; Ajayi, S.O.; Bilal, M.; Alaka, H.A.; Owolabi, H.A.; Arawomo, O.O. Designing Out Construction Waste Using BIM Technology: Stakeholders' Expectations for Industry Deployment. J. Clean. Prod. 2018, 180, 375-385. [CrossRef]

42. Duan, H.; Wang, J.; Huang, Q. Encouraging the Environmentally Sound Management of C\&D Waste in China: An Integrative Review and Research Agenda. Renew. Sustain. Energy Rev. 2015, 43, 611-620. [CrossRef]

43. Yu, A.T.W.; Poon, C.S.; Wong, A.; Yip, R.; Jaillon, L. Impact of Construction Waste Disposal Charging Scheme on Work Practices at Construction Sites in Hong Kong. Waste Manag. 2013, 33, 138-146. [CrossRef] [PubMed]

44. Poon, C.S.; Yu, A.T.W.; Wong, A.; Yip, R. Quantifying the Impact of Construction Waste Charging Scheme on Construction Waste Management in Hong Kong. J. Constr. Eng. Manag. 2013, 139, 466-479. [CrossRef]

45. Akinade, O.O.; Oyedele, L.O.; Munir, K.; Bilal, M.; Ajayi, S.O.; Owolabi, H.A.; Alaka, H.A.; Bello, S.A. Evaluation Criteria for Construction Waste Management Tools: Towards a Holistic BIM Framework. Int. J. Sustain. Build. Technol. Urban. Dev. 2016, 7,3-21. [CrossRef]

46. Newaz, M.T.; Davis, P.; Sher, W.; Simon, L. Factors Affecting Construction Waste Management Streams in Australia. Int. J. Constr. Manag. 2020. [CrossRef] 
47. Akinade, O.O.; Oyedele, L.O.; Bilal, M.; Ajayi, S.O.; Owolabi, H.A.; Alaka, H.A.; Bello, S.A. Waste Minimisation Through Deconstruction: A BIM Based Deconstructability Assessment Score (BIM-DAS). Resour. Conserv. Recy. 2015, 105, 167-176. [CrossRef]

48. Lu, W.; Yuan, H. A Framework for Understanding Waste Management Studies in Construction. Waste Manag. 2011, 31, 1252-1260. [CrossRef] [PubMed]

49. Won, J.; Cheng, J.C.P.; Lee, G. Quantification of Construction Waste Prevented by BIM-Based Design Validation: Case Studies in South Korea. Waste Manag. 2016, 49, 170-180. [CrossRef]

50. Kim, Y.C.; Hong, W.H.; Park, J.W.; Cha, G.W. An Estimation Framework for Building Information Modeling (BIM)-Based Demolition Waste by Type. Waste Manag. Res. 2017, 35, 1285-1295. [CrossRef]

51. Ganiyu, S.A.; Oyedele, L.O.; Akinade, O.; Owolabi, H.; Akanbi, L.; Gbadamosi, A. BIM Competencies for Delivering WasteEfficient Building Projects in a Circular Economy. DIBE 2020, 4, 100036. [CrossRef]

52. Guerra, B.C.; Leite, F.; Faust, K.M. 4D-BIM to Enhance Construction Waste Reuse and Recycle Planning: Case Studies on Concrete and Drywall Waste Streams. Waste Manag. 2020, 116, 79-90. [CrossRef] [PubMed]

53. Cheng, J.C.P.; Ma, L.Y.H. A BIM-Based System for Demolition and Renovation Waste Estimation and Planning. Waste Manag. 2013, 33, 1539-1551. [CrossRef]

54. Hamidi, B.; Bulbul, T.; Pearce, A.; Thabet, W. Potential Application of BIM in Cost-Benefit Analysis of Demolition Waste Management. Constr. Res. Congr. 2014, 2014, 29. [CrossRef]

55. Akbarnezhad, A.; Ong, K.C.G.; Chandra, L.R. Economic and Environmental Assessment of Deconstruction Strategies Using Building Information Modeling. Autom. Constr. 2014, 37, 131-144. [CrossRef]

56. Zoghi, M.; Kim, S. Dynamic Modeling for Life Cycle Cost Analysis of BIM-Based Construction Waste Management. Sustainability 2020, 12, 2483. [CrossRef]

57. Zanghelini, G.M.; Cherubini, E.; Soares, S.R. How Multi-Criteria Decision Analysis (MCDA) Is Aiding Life Cycle Assessment (LCA) in Results Interpretation. J. Clean. Prod. 2018, 172, 609-622. [CrossRef]

58. Jalaei, F.; Zoghi, M.; Khoshand, A. Life Cycle Environmental Impact Assessment to Manage and Optimize Construction Waste Using Building Information Modeling (BIM). Int. J. Constr. Manag. 2019, 21, 784-801. [CrossRef]

59. Soust-Verdaguer, B.; Llatas, C.; García-Martínez, A. Critical Review of Bim-Based LCA Method to Buildings. Energy Build. 2017, 136, 110-120. [CrossRef]

60. Peng, C. Calculation of a Building's Life Cycle Carbon Emissions Based on Ecotect and Building Information Modeling. J. Clean. Prod. 2016, 112, 453-465. [CrossRef]

61. Shin, Y.S.; Cho, K. BIM Application to Select Appropriate Design Alternative with Consideration of LCA and LCCA. Math. Probl. Eng. 2015, 2015, 281640. [CrossRef]

62. Kehily, D.; Underwood, J. Embedding Life Cycle Costing in 5D BIM. J. Inf. Technol. Constr. 2017, 22, 145-167.

63. Lee, S.; Tae, S.; Roh, S.; Kim, T. Green Template for Life Cycle Assessment of Buildings Based on Building Information Modeling: Focus on Embodied Environmental Impact. Sustainability 2015, 7, 16498-16512. [CrossRef]

64. Jalaei, F.; Jrade, A. Integrating Building Information Modeling (BIM) and Energy Analysis Tools with Green Building Certification System to Conceptually Design Sustainable Buildings. J. Inf. Technol. Constr. 2014, 19, 494-519. [CrossRef]

65. Marrero, M.; Wojtasiewicz, M.; Martínez-Rocamora, A.; Solís-Guzmán, J.; Alba-Rodríguez, M.D.; Bim, L.C.A. Integration for the Environmental Impact Assessment of the Urbanization Process. Sustainability 2020, 12, 4196. [CrossRef]

66. Eadie, R.; Browne, M.; Odeyinka, H.; McKeown, C.; McNiff, S. BIM Implementation Throughout the UK Construction Project Lifecycle: An Analysis. Autom. Constr. 2013, 36, 145-151. [CrossRef]

67. Jung, W.; Lee, G. The Status of BIM Adoption on Six Continents. Int. J.; Civil, Struct. Constr. Archit. Eng. 2015, 9, 406-410.

68. Kim, K.P.; Ma, T.; Sigh, A.B.; Zhang, C.; Hui, K.M. (2018-16) Investigation of Readiness for 4D and 5D BIM Adoption in the Australian Construction Industry. Manag. Rev. 2018, 11, 43-64.

69. Ding, T.; Xiao, J. Estimation of Building-Related Construction and Demolition Waste in Shanghai. Waste Manag. 2014, 34, 2327-2334. [CrossRef] [PubMed]

70. Liu, Z.; Osmani, M.; Demian, P.; Baldwin, A. A BIM-Aided Construction Waste Minimisation Framework. Autom. Constr. 2015, 59, 1-23. [CrossRef]

71. Lu, W.; Webster, C.; Chen, K.; Zhang, X.; Chen, X. Computational Building Information Modelling for Construction Waste Management: Moving from Rhetoric to Reality. Renew. Sustain. Energy Rev. 2017, 68, 587-595. [CrossRef]

72. Rašković, M.; Ragossnig, A.M.; Kondracki, K.; Ragossnig-Angst, M. Clean Construction and Demolition Waste Material Cycles Through Optimised Pre-Demolition Waste Audit Documentation: A Review on Building Material Assessment Tools. Waste Manag. Res. 2020, 38, 923-941. [CrossRef] [PubMed]

73. Wang, C.; Cho, Y.K.; Kim, C. Automatic BIM Component Extraction from Point Clouds of Existing Buildings for Sustainability Applications. Autom. Constr. 2015, 56, 1. [CrossRef]

74. Fathi, H.; Dai, F.; Lourakis, M. Automated as-Built 3D Reconstruction of Civil Infrastructure Using Computer Vision: Achievements, Opportunities, and Challenges. Adv. Eng. Inform. 2015, 29, 149-161. [CrossRef]

75. Lu, Q.; Lee, S. Image-Based Technologies for Constructing As-Is Building Information Models for Existing Buildings. J. Comput. Civ. Eng. 2017, 31, 652. [CrossRef] 
76. Bhatla, A.; Choe, S.Y.; Fierro, O.; Leite, F. Evaluation of Accuracy of as-Built 3D Modeling from Photos Taken by Handheld Digital Cameras. Autom. Constr. 2012, 28, 116-127. [CrossRef]

77. Xiong, X.; Adan, A.; Akinci, B.; Huber, D. Automatic Creation of Semantically Rich 3D Building Models from Laser Scanner Data. Autom. Constr. 2013, 31, 325-337. [CrossRef]

78. Ge, X.J.; Livesey, P.; Wang, J.; Huang, S.; He, X.; Zhang, C. Deconstruction Waste Management Through 3-d Reconstruction and Bim: A Case Study. Vis. Eng. 2017, 5, 505. [CrossRef]

79. Jung, J.; Hong, S.; Jeong, S.; Kim, S.; Cho, H.; Hong, S.; Heo, J. Productive Modeling for Development of as-Built BIM of Existing Indoor Structures. Autom. Constr. 2014, 42, 68-77. [CrossRef]

80. Hong, S.; Jung, J.; Kim, S.; Cho, H.; Lee, J.; Heo, J. Semi-Automated Approach to Indoor Mapping for 3D as-Built Building Information Modeling. Comput. Environ. Urban. Syst. 2015, 51, 34-46. [CrossRef]

81. Volk, R.; Luu, T.H.; Mueller-Roemer, J.S.; Sevilmis, N.; Schultmann, F. Deconstruction Project Planning of Existing Buildings Based on Automated Acquisition and Reconstruction of Building Information. Autom. Constr. 2018, 91, 226-245. [CrossRef]

82. Cheng, B.; Li, J.; Tam, V.W.Y.; Yang, M.; Chen, D. A BIM-LCA Approach for Estimating the Greenhouse Gas Emissions of Large-Scale Public Buildings: A Case Study. Sustainability 2020, 12, 685. [CrossRef]

83. Xu, J.; Shi, Y.; Xie, Y.; Zhao, S. A BIM-Based Construction and Demolition Waste Information Management System for Greenhouse Gas Quantification and Reduction. J. Clean. Prod. 2019, 229, 308-324. [CrossRef]

84. Díaz-Vilariño, L.; Lagüela, S.; Armesto, J.; Arias, P. Semantic As-Built 3D Models Including Shades for the Evaluation of Solar Influence on Buildings. Sol. Energy 2013, 92, 269-279. [CrossRef]

85. O'Keeffe, S.; Bosché, F. The Need for Convergence of BIM and 3D Imaging in the Open World. CITA BIM Gather. 2015, 1, 109-116.

86. Hossain, M.A.; Yeoh, J.K.W. BIM for Existing Buildings: Potential Opportunities and Barriers. IOP Conf. Ser. Mater. Sci. Eng. 2018, 371. [CrossRef]

87. Wong, J.K.W.; Ge, J.; He, S.X. Digitisation in Facilities Management: A Literature Review and Future Research Directions. Autom. Constr. 2018, 92, 312-326. [CrossRef]

88. Wong, J.K.W.; Zhou, J. Enhancing Environmental Sustainability over Building Life Cycles Through Green BIM: A Review. Autom. Constr. 2015, 57, 156-165. [CrossRef]

89. Akanbi, L.A.; Oyedele, L.O.; Akinade, O.O.; Ajayi, A.O.; Davila Delgado, M.; Bilal, M.; Bello, S.A. Salvaging Building Materials in a Circular Economy: A BIM-Based Whole-Life Performance Estimator. Resour. Conserv. Recy. 2018, 129, 175-186. [CrossRef]

90. Barki, H.; Fadli, F.; Shaat, A.; Boguslawski, P.; Mahdjoubi, L. BIM Models Generation from 2D CAD Drawings and 3D Scans: An Analysis of Challenges and Opportunities for AEC Practitioners. Build. Inf. Model. (BIM) Des. Constr. Oper. 2015, 1, 369-380. [CrossRef]

91. Díaz-Vilariño, L.; Martínez-Sánchez, J.; Lagüela, S.; Armesto, J.; Khoshelham, K. Door Recognition in Cluttered Building Interiors Using Imagery and LiDAR Data. Int. Arch. Photogramm. Remote Sens. Spatial. Inf. Sci. ISPRS Arch. 2014, 40, 203-209. [CrossRef]

92. Liu, X.; Eybpoosh, M.; Akinci, B. Developing as-Built Building Information Model Using Construction Process History Captured by a Laser Scanner and a Camera. In Proceedings of the Construction Research Congress Construction Challenges in a Flat World, West Lafayette, IN, USA, 21-23 May 2012.

93. Patraucean, V.; Armeni, I.; Nahangi, M.; Yeung, J.; Brilakis, I.; Haas, C. State of Research in Automatic As-Built Modelling. In Proceedings of the 32nd International Symposium on Automation and Robotics in Construction and Mining: Connected to the Future, Oulu, Finland, 15-18 June 2015.

94. Volk, R.; Stengel, J.; Schultmann, F. Building Information Modeling (BIM) for Existing Buildings- Literature Review and Future Needs. Autom. Constr. 2014, 38, 109-127. [CrossRef]

95. Wang, J.; Huang, S.; Zhao, L.; Ge, J.; He, S.; Zhang, C.; Wang, X. High Quality 3D Reconstruction of Indoor Environments Using RGB-D Sensors. In Proceedings of the 2017 12th IEEE Conference on Industrial Electronics and Applications, ICIEA 2017, Siem Reap, Cambodia, 18-20 June 2017; pp. 1739-1744. [CrossRef]

96. Santos, R.; Costa, A.A.; Silvestre, J.D.; Pyl, L. Integration of LCA and LCC Analysis Within a BIM-Based Environment. Autom. Constr. 2019, 103, 127-149. [CrossRef]

97. Santos, R.; Costa, A.A.; Silvestre, J.D.; Pyl, L. Informetric Analysis and Review of Literature on the Role of BIM in Sustainable Construction. Autom. Constr. 2019, 103, 221-234. [CrossRef]

98. Carvalho, J.P.; Alecrim, I.; Bragança, L.; Mateus, R. Integrating BIM-Based LCA and Building Sustainability Assessment. Sustainability 2020, 12, 468. [CrossRef] 